\title{
A REDEFINIÇÃO DA BIBLIOTECA NO SÉCULO XXI: DE AMBIENTES INFORMACIONAIS A ESPAÇOS DE CONVIVÊNCIA
}

THE LIBRARY REEDEFINIÇÃO ST CENTURY:
INFORMATIONAL ENVIRONMENTS TO LIVE TOGETHER SPACES
LA BIBLIOTECA RESTABLECER EL SIGLO XXI:
ENTORNOS INFORMATIVOS A VIVIR JUNTOS ESPACIOS
Jorge Santa Anna

\section{RESUMO}

As constantes transformações ocorridas ao longo dos tempos representam fatores interferentes no posicionamento e na estruturação das bibliotecas, de modo que essas instituições redefinem constantemente seus produtos e serviços oferecidos à sociedade. A trajetória histórica da biblioteca demonstra que ela é uma unidade adaptativa, adquirindo novas características a partir das tendências e exigências dos usuários e das inovações tecnológicas. Assim, este artigo objetiva demonstrar o novo cenário que se idealiza para a biblioteca do futuro, na percepção da literatura e de bibliotecários. Para tanto, o estudo apresenta a evolução da biblioteca ao longo dos anos; expõe os serviços e produtos oferecidos com base nas novas tecnologias; discorre acerca das atividades culturais e entretenimento realizadas nos espaços informacionais; e, por fim, reflete a opinião de bibliotecários quanto às atividades culturais/sociais realizadas nas bibliotecas. Através de pesquisa bibliográfica e estudo aplicado a bibliotecários, os resultados confirmaram que, no presente, a biblioteca extrapolou sua função meramente informacional, exercendo também funções sociais. Presume-se que no futuro, a biblioteca ampliará suas funções deixando de ser um ambiente meramente informacional para transformar-se em espaços de convivência.

PALAVRAS-CHAVE: Bibliotecas híbridas. Evolução tecnológica. Função informacional - Bibliotecas. Função social - Bibliotecas.

\section{ABSTRACT}

The constant changes that occur over time represent interfering factors in the positioning and the structuring of the libraries, so that these institutions constantly redefine their products and services to society. The historical trajectory of the library demonstrates that it is an adaptive unit, acquiring new features from the trends and requirements of users and technological innovations. Thus, this article aims to demonstrate the new scenario that envisions for tomorrow's library, in the perception of literature and librarians. To this end, the study shows the evolution of the library over the years; exposes the services and products offered based on new technologies; talks about cultural activities and entertainment held in the information spaces; and, finally, reflects the opinion of librarians about the cultural / social activities in libraries. Through bibliographical research and study applied to librarians, the results confirmed that, at present, the library went beyond its purely informational function, also performing social functions. It is assumed that in the future, the library will expand its functions ceasing to be purely informational environment to turn into living spaces.

KEYWORDS: Hybrid libraries. Technological evolution. Informational function - Libraries. Social function - Libraries.

\footnotetext{
1 Graduado em Biblioteconomia pela Universidade Federal do Espírito Santo (UFES). Professor de Departamento de Biblioteconomia da UFES. Vitória, Espírito Santo - Brasil. http://orcid.org/0000-0002-07093639. E-mail: jorjao20@yahoo.com.br

Submetido em: 11/11/2015 - Aceito em: 07/03/2016.

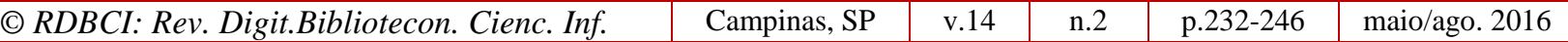




\section{RESUMEN}

Los constantes cambios que se producen con el tiempo representan los factores que interfieren en el posicionamiento y la estructuración de las bibliotecas, de modo que estas instituciones constantemente redefinen sus productos y servicios a la sociedad. La trayectoria histórica de la biblioteca demuestra que es una unidad adaptativa, adquiriendo nuevas características de las tendencias y necesidades de los usuarios y las innovaciones tecnológicas. Por lo tanto, este artículo tiene como objetivo demostrar el nuevo escenario que se vislumbra para la biblioteca de mañana, en la percepción de la literatura y los bibliotecarios. Con este fin, el estudio muestra la evolución de la biblioteca lo largo de los años; expone los servicios y productos que ofrece sobre la base de las nuevas tecnologías; habla de las actividades culturales y de entretenimiento, celebrada en los espacios de información; y, por último, refleja la opinión de los bibliotecarios acerca de las actividades culturales / sociales en las bibliotecas. A través de la investigación bibliográfica y estudio aplicado a los bibliotecarios, los resultados confirmaron que, en la actualidad, la biblioteca fue más allá de su función meramente informativa, también realizar funciones sociales. Se supone que en el futuro, la biblioteca ampliará sus funciones dejar de ser entorno puramente informativo para convertirse en espacios de vida.

PALABRAS ClAVE: Bibliotecas híbridas. Los desarrollos tecnológicos. Función Informativo Bibliotecas. Función social - Bibliotecas.

\section{INTRODUÇÃ̃o}

Nos últimos anos, os reflexos das novas tecnologias têm proporcionado grandes mudanças nas unidades e nos serviços de informação. No caso específico das bibliotecas, alguns questionam qual será o verdadeiro papel dessas unidades diante dos novos suportes tecnológicos, que passam a ser disponibilizados em ambiente digital, gerando novas demandas e uso da informação.

A informação disponibilizada no ciberespaço ${ }^{2}$ adquire uma nova dimensão, o que requer a oferta de produtos e serviços gerenciados a partir das novas tecnologias da informação e comunicação, por conseguinte, ocasionando novas práticas bibliotecárias. $\mathrm{O}$ aparecimento da biblioteca digital tem se mostrado como uma realidade inquestionável (DIAS, 2007), a qual transfigura os fazeres dos bibliotecários para um novo contexto, conduzidos por meio dos novos artefatos tecnológicos.

Diante dessa nova realidade, percebe-se que o trabalho desenvolvido por bibliotecários adquire novas dimensões, de modo que esses profissionais ampliam seus postos de trabalho, adequando-se conforme as necessidades dos usuários da informação. Esse fato, segundo Santa Anna (2015), demonstra o quanto a área é adaptativa, transfigurando o perfil profissional dos bibliotecários, os quais deixam de vincularem-se, unicamente, às tradicionais bibliotecas físicas, para aturem em novas ambiências, por meio de um perfil desinstitucionalizado.

A literatura de Biblioteconomia e Ciência da Informação é ampla no que se refere às transformações no âmbito das bibliotecas físicas e as novas práticas profissionais geradas com a revolução tecnológica (LANCASTER, 1983; BAPTISTA, 2000; CUNHA, 2010;

${ }^{2}$ Refere-se ao espaço digital. Termo utilizado por Pierre Lévy (2000) para designar o novo espaço de relacionamento e disponibilização da informação, sustentado por meio de recursos tecnológicos e viabilizado pelo uso da internet.

(C) RDBCI: Rev. Digit.Bibliotecon. Cienc. Inf.

Campinas, SP

v.14

p. $232-246$

maio/ago. 2016 
SANTA ANNA, 2015, dentre outros). Todavia, de forma exagerada, muitos presumem o desaparecimento das unidades físicas, sobretudo com o aparecimento das bibliotecas digitais e com a diminuição dos recursos informacionais em suporte impresso.

As previsões sobre o desaparecimento da profissão e da instituição biblioteca foram refutadas no estudo de Santa Anna (2014). No que se refere ao futuro das bibliotecas físicas, acredita-se que elas sobreviverão durante muito tempo, uma vez que essas instituições têm se tornado cada dia mais híbridas, oferecendo tecnologias sofisticadas, sem, contudo, eliminar as tecnologias tradicionais, satisfazendo a amplitude das necessidades demandadas por seu diversificado público.

Além disso, essa previsão não abrange todas as funções cabíveis à biblioteca e seus profissionais. Santa Anna, Gregório e Gerlin (2014) afirmam que a biblioteca não exerce uma função puramente técnica, voltada à educação/informação, mas também deve exercer a função social e cultural. Assim, mesmo que as coleções impressas sejam, no futuro, migradas para o ciberespaço, fortalecendo a biblioteca digital, presume-se que a biblioteca física, ao invés de desaparecer, direcionará seu compromisso em prol das funções sociais e culturais.

Já Flusser (1982, p. 230) menciona em seu estudo que a biblioteca deve se manifestar por sua função social, ou seja, segundo esse autor, a função social da biblioteca, com o passar dos tempos "[...] não seria mais a de ser museu ou supermercado de livros, mas um espaço de diálogo. Diálogo entre os seus usuários e entre leitores e livros."

Essas discussões despertam uma nova concepção para a Biblioteconomia do futuro, de modo que sejam oferecidos produtos e serviços que atendam as necessidades da comunidade servida, não sendo essas necessidades, necessariamente, informacionais. A biblioteca deve, na contemporaneidade, adquirir uma nova faceta, investigando o perfil dos usuários e a eles se adequando, tornando-se um espaço de socialização, oferecendo subsídios para auxiliar a vida de seus usuários. Assim, o foco das atividades não estará no acervo, mas nas pessoas e suas necessidades sociais ${ }^{3}$.

Sendo assim, este estudo objetiva demonstrar o novo cenário que se idealiza para a biblioteca do futuro, na percepção da literatura e de bibliotecários. Para tanto, o estudo apresenta a evolução da biblioteca ao longo dos anos; expõe os serviços e produtos oferecidos com base nas novas tecnologias; discorre acerca das atividades culturais e entretenimento realizado nos espaços informacionais; e, por fim, reflete a opinião de bibliotecários quanto às atividades culturais/sociais realizadas nas bibliotecas.

\footnotetext{
${ }^{3}$ Informação verbal. Palestra proferida no XXVI Congresso Brasileiro de Biblioteconomia e Documentação (CBBD), no ano de 2015, por Elisa Delfini Correa, intitulada "Aumente suas expectativas", cuja fundamentação atrelou-se às propostas defendidas por David Lankes (2012).

(C) RDBCI: Rev. Digit.Bibliotecon. Cienc. Inf. $\quad$ Campinas, SP

v.14

p.232-246

maio/ago. 2016
} 


\section{METOdOLOGIA: PESQUISA BIBLIOgRÁfICA E ESTUdO DE OBSERVAÇÃo}

Este estudo caracteriza-se como pesquisa qualitativa, cujo objetivo é investigar, por meio de levantamento bibliográfico e análise de artigos, o que vem sendo publicado sobre a temática em apreço. Além disso, realizou-se estudo de observação, através da aplicação de entrevista a cinco bibliotecários atuantes em diferentes contextos (bibliotecas).

O estudo bibliográfico foi conduzido por meio de levantamento realizado nas bases Scielo, Google Acadêmico e Brapci, investigando o que vem sendo publicado sobre a evolução e o futuro das bibliotecas. Consultaram-se as referidas bases, utilizando-se dos descritores "bibliotecas do futuro"; "bibliotecas digitais - novas tecnologias" "bibliotecas espaços de convivência" e "bibliotecas - evolução histórica". Assim, resgataram-se inúmeros artigos publicados nos últimos dez anos. Após leitura do título e do resumo desses artigos, selecionaram-se dezenove artigos, os quais discorrem acerca da evolução das bibliotecas e dos serviços e produtos oferecidos por essas instituições, e as novas projeções para as bibliotecas físicas no futuro.

No que se refere ao estudo de observação, investigou-se a opinião de cinco bibliotecários atuantes em diferentes modalidades de biblioteca (pública, escolar, universitária, acadêmica e especializada) a respeito das atividades sociais e culturais realizadas nas referidas bibliotecas, e a percepção desses profissionais a respeito do futuro da biblioteca física.

A seguir, apresentam-se a evolução das bibliotecas e dos produtos e serviços biblioteconômicos ao longo dos tempos, e as projeções para o futuro, com base no que menciona a literatura da área e o que considera os profissionais entrevistados.

\section{3 a evolução das biblotecas e dos serviços es produtos BIBLIOTECÁRIOS}

A existência das unidades de informação remete aos povos da Antiguidade. Desde o momento que a informação passou a ser registrada, a criação de espaços para abrigar os suportes informacionais constituiu uma necessidade imprescindível. No entanto, nessa época, a preocupação estava na guarda e preservação dos documentos. No decorrer dos tempos, "[...] as mudanças técnicas, como o uso do papel e a invenção da imprensa, tornaram a biblioteca mais acessível e seu caráter passou de instituição fechada e particular para leiga e pública" (SANTOS, 2012, p. 187).

Silveira (2008) comenta que a biblioteca não perdeu as concepções que a sustentaram como instituições sociais a serviço da informação, educação e cultura gerada pelas sociedades. Contudo, a evolução tecnológica viabilizou novas necessidades, o que fez despertar a mudança de perfil do profissional, de modo que essas unidades remodelassem seus produtos e serviços, preocupando-se, essencialmente, com a gestão dos sistemas, suportes e tecnologias informacionais. 
Os diferentes períodos históricos foram responsáveis pelas configurações em que as bibliotecas foram submetidas. Na sociedade atual, caracterizada como Sociedade da Informação, colocam-se novas exigências às bibliotecas e aos profissionais que as conduzem. Essa sociedade mutante, globalizada e informatizada provoca diversas mudanças às bibliotecas, tornando-as "[...] centros de informação e pesquisa, e seus bibliotecários, situados como organizadores, coletores e socializadores de informações específicas" (MADUREIRA; VILARINHO, 2010, p. 90).

Segundo estudo proferido por Benício e Silva (2005), a evolução dos suportes de informação proporcionou diferentes estágios às bibliotecas ao longo dos tempos. Essa evolução demonstra a capacidade de se adaptar em novos contextos, sendo a biblioteca uma organização adaptativa. Por conseguinte, presume-se que, no futuro, as bibliotecas, juntamente com os serviços e produtos que elas geram ao armazenar e disponibilizar informação em diferentes suportes, serão cada vez mais híbridas.

Notam-se mudanças de paradigmas, as quais foram responsáveis pela adequação da biblioteca ao contexto em que estava inserida, influenciada por necessidades diferentes, haja vista as tendências e costumes presentes nas civilizações. De modo geral, Santa Anna (2015) cita dois principais paradigmas, considerando-os como os maiores influenciadores e diferenciadores entre a biblioteca tradicional e a biblioteca moderna: paradigma da posse e do acesso à informação.

De modo geral, o paradigma do acesso é concebido a partir do uso das tecnologias da informação e comunicação. Assim, antes do uso das novas tecnologias, as bibliotecas forneciam serviços e produtos, com o intuito de garantir ao usuário a posse da informação, estando ela materializada em diferentes suportes e esses incorporados, por meio das técnicas e instrumentos de organização, às coleções físicas, que, por sua vez, formavam os grandes acervos bibliográficos (SANTA ANNA, 2015). No paradigma do acesso, ao contrário do anterior,

[...] as atenções dos profissionais transferem-se do acervo para o próprio usuário, ou seja, as preocupações estão mais envolvidas com o usuário e suas necessidades do que com a posse informacional. Essa nova tendência fez apontar o nascimento de uma nova modalidade de biblioteca, a Biblioteca Virtual, amparada por instrumentos tecnológicos de alta capacidade, os quais facilitam o tratamento e viabilizam o intercâmbio de informações em velocidades espantosas (SANTA ANNA, 2015, p. 140).

Ao permitir o acesso à informação, a biblioteca, sobretudo a pública, está contribuindo com a aprendizagem que, por sua vez, garante a produção de conhecimentos. Portanto, ao oferecer informação e garantir a expansão do conhecimento na sociedade, essas unidades colocam-se a serviço da cidadania, por conseguinte, consolida-se seu papel social (BERNARDINO; SUAIDEN, 2011).

Está claro que as bibliotecas modernas visam à garantia do acesso às informações, sendo essa uma das atividades principais das coleções disponibilizadas e geridas pelas novas 
tecnologias. Porém, é consenso na literatura de que, ao longo dos tempos, a biblioteca ampliou suas funções, oferecendo produtos e serviços que extravasem, tão somente, a prestação de serviços e produtos de informação.

A respeito da ampliação das funções exercidas por uma biblioteca na sociedade, Silveira e Reis (2011, p. 37) defendem que as bibliotecas devem ser consideradas como "lugares de práticas culturais". Os autores justificam essa afirmação descrevendo que essas instituições ajudam a "[...] elaborar representações para os diversos cenários sociais, políticos e culturais onde nossas vidas se desenvolvem, fazendo frutificar os saberes e contribuindo para a preservação e difusão do patrimônio material e intelectual humano".

Entende-se que a biblioteca vem se transformando ao longo dos tempos no sentido de oferecer às pessoas aquilo que elas necessitam. Assim, os produtos e serviços oferecidos por essas instituições não devem limitar-se apenas ao acervo, estando o profissional focado somente nas técnicas e instrumentos de tratamento e disponibilização de documentos (OLIVEIRA; ALVES; MAIA, 2013).

Desse modo, a biblioteca do futuro amplia seu escopo de atuação, satisfazendo as necessidades das comunidades, dos grupos sociais, enfim, dos cidadãos. Entende-se que a biblioteca na atualidade deve ser diversificada naquilo que oferece, tendo como produto de investigação, principalmente, as pessoas, preocupando-se com o outro e viabilizando produtos e serviços para o outro (SILVEIRA, 2014). Esse fato garante uma participação mais humanista do bibliotecário no âmbito das transformações sociais.

No que se refere ao estudo de observação realizado em cinco bibliotecas, conduzido por meio da entrevista aos bibliotecários gestores dessas unidades, evidenciou-se o quanto essas unidades vão diversificando seus produtos e serviços ao longo do tempo. Em três unidades, o processo de automação já se faz presente, enquanto em duas bibliotecas, não se faz uso de recursos automatizados, recorrendo aos métodos tradicionais de organização e disponibilização da informação. No que se refere às atividades recreativas e culturais, notouse que todas as unidades possuem preocupações em prestar assistência social às comunidades.

\section{AS BIBLIOTECAS E AS FUNÇõES SOCIAL E CULTURAL}

O papel social da biblioteca e do bibliotecário não constitui uma reflexão recente. Ao contrário, essa discussão teve início a partir da expansão das bibliotecas públicas, as quais foram influenciadas pelos ideais democráticos e liberais propostos pelos grandes movimentos sociais e emancipatórios do século XVIII e XIX (MILANESI, 2002).

Em essência, o contexto social conduzido pelo Estado Democrático viabiliza a necessidade e valorização de projetos e programas que visem à disseminação da cultura e da cidadania na sociedade. As bibliotecas inseridas nesse contexto adquirem preocupações inovadoras, devendo se configurar como "[...] lugares de identidade e de enraizamento. 
Lugares de cultura e de socialização. Espaços de mediação informacional e de produção do conhecimento [...]" (SILVEIRA, 2014, p. 147, grifo nosso).

Sendo espaços de conhecimento e de socialização, as práticas realizadas não podem fechar-se ao tecnicismo; ao contrário, devem-se priorizar condições para que os indivíduos percebam a importância da biblioteca no fomento às transformações individuais e sociais. Assim, para que novos serviços e produtos sejam desenvolvidos e geridos com efetividade, não resta dúvida de que novas competências, sobretudo as de cunho pedagógico devam ser desenvolvidas pelos bibliotecários contemporâneos (SANTA ANNA; PEREIRA; CAMPOS, 2014). Assim, é importante refletir que

\begin{abstract}
[são] os serviços [...] que vão conferir à biblioteca sua dinâmica, sua capacidade de transpor a métrica e estabilidade de seus acervos, permitindo a concretização da sua função social. Essa função social pede uma relação constante entre o que se pode chamar de corpus da biblioteca, suportes documentais, pessoal, informação, conhecimento, cultura e público utilizador (RACHE; VARVAKIS, 2006, p.137 apud BERNARDINO; SUAIDEN, 2011, p. 38).
\end{abstract}

Para que os serviços bibliotecários direcionem-se em prol da função social, é preciso que essas unidades de informação tenham um olhar mais diferenciado quanto à dotação de seus acervos e, principalmente, no que tange à contratação de bibliotecário, tendo em vista permitir uma inserção forte na sociedade e, ao mesmo tempo, efetive o cumprimento de suas funções enquanto ambiente favorável à interação entre informação e conhecimento (BERNARDINO; SUAIDEN, 2011).

Os referidos autores acreditam que a biblioteca na sociedade atual, com ênfase na biblioteca pública, somente expandirá suas atividades, sendo reconhecida como instituição social que contribui com o desenvolvimento pessoal dos cidadãos e com o crescimento social, político e econômico da nação em que está inserida, se houver atuação mais árdua e intensa dos bibliotecários no que se refere à elaboração e condução de projetos que ultrapassem os "muros" das bibliotecas físicas, atingindo o cotidiano da sociedade.

Como exemplo da elaboração em projetos sociais, sobretudo àqueles ligados à cultura social, citam-se projetos de apoio e/ou incentivo à prática da leitura, cujo objetivo dessas intervenções seja interagir com a comunidade usuária, fato esse que proporcionará à biblioteca, a princípio, condições apropriadas para firmar seu papel, enquanto fomentadora da cultura na sociedade (BERNARDINO; SUAIDEN, 2011).

Bezerra e Silva (2011, p. 6) consideram que as bibliotecas, independente se pública ou privada, deve possuir como uma de suas principais finalidades contribuir com a efetivação do exercício da cidadania. Essas autoras atribuem à leitura uma atividade que desperta nas pessoas "[...] a postura consciente, reflexiva e crítica frente à realidade social em que vivem e atuam $[\ldots] "$.

Ao realizar atividades inovadoras nos espaços físicos destinados a armazenar a informação registrada, pretende-se transfigurar esses ambientes, considerados por muito 
tempo como "locais de guarda e preservação da memória" para caracterizá-los como espaços de socialização, de encontro e de trocas de informações o que favorece a produção de novos conhecimentos.

Sendo assim, segundo Santa Anna, Zanetti e Nascimento (2015, p. 80), as ações desenvolvidas pelo bibliotecário não podem estar engessadas unicamente a fazeres tradicionais e técnicos, como as atividades de tratamento informacional, mas devem extrapolar essas práticas. Citam como exemplo o potencial das bibliotecas localizadas em presídios, demonstrando o papel educacional, cultural e ressocializador desses espaços específicos de informação.

Logo, os autores supracitados consideram que o perfil almejado ao bibliotecário para que essas funções sociais/culturais sejam concretizadas deve ser de um agente social, contribuindo na consolidação da cidadania, de modo a garantir com a formação pessoal e social de um indivíduo, por conseguinte, despertando valiosas contribuições no desenvolvimento social e econômico de toda a sociedade.

No entendimento de Silveira e Reis (2011), o papel social da biblioteca deveria se revestir de quatro funções primordiais, quais sejam: função cultural, informacional, recreativa e educacional. Funções informacional e cultural referem-se, de modo geral, à oferta de produtos e serviços informacionais, os quais agregam valor instrutivo para os usuários, conduzindo a produção de conhecimentos e posicionamento crítico e transformador ao indivíduo.

Já as funções cultural e recreativa, que praticamente são complementares, provocam diferenciais aos fazeres biblioteconômicos, cujo objetivo dessa inovação seja viabilizar à sociedade a manifestação da identidade social, de acordo com o perfil da comunidade onde está inserida. Assim, a biblioteca deve ser espaço de preservação da memória e do patrimônio cultural, artístico e literário que institui em meio aos movimentos racionais de uma dada localidade. Nesse âmago, essas unidades passam a serem consideradas "[...] locais de representação coletiva onde aquilo que chamamos de identidade encontra solo profícuo para nutrir-se e valorizar-se" (SILVEIRA; REIS, 2011, p. 52).

O estudo dos autores supracitados demonstra, para o contexto atual, a necessidade das bibliotecas oferecerem produtos e serviços dos mais diferenciados, permitindo o equilíbrio e, ao mesmo tempo, a junção de diferentes práticas. Sendo assim,

\footnotetext{
$\mathrm{Na}$ modernidade, além das atividades de coleta, organização, preservação e disseminação do escrito, as bibliotecas devem participar ativamente do processo de construção sócio-histórica das múltiplas paisagens culturais que conferem visibilidade ao lugar onde estão inseridas (SILVEIRA; REIS, 2011, p. 52).
}

É importante citar, ao considerar a biblioteca como espaços de socialização, de troca de informação, de aprendizado e de encontro, as diversas atividades culturais e recreativas que podem ser desenvolvidas nesses espaços. No que se refere às ações culturais, a pesquisa de Rosa (2009) demonstrou que as bibliotecas, independente da modalidade a que pertençam,

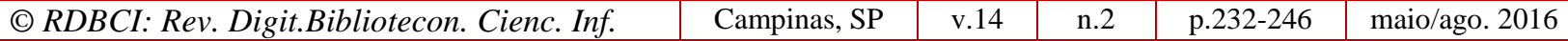


devem planejar, conduzir e viabilizar práticas culturais, tornando-se centros disseminadores da cultura.

Segundo essa autora, a ação cultural não se limita somente à disponibilização dos bens culturais; deve possibilitar também a participação e a criação de novos bens culturais e conhecimentos. Nesse contexto, fica evidenciado que o bibliotecário deve proporcionar um ambiente para que o usuário participe, no sentido de opinar, formular e criar.

A função recreativa insere-se na biblioteca quando ela passa a ser vista como instituição social e democrática, a serviço da comunidade, constituindo espaços de convivência. No entendimento de Gonçalves (2011, p. 62), a partir dessa ótica, “[...] uma biblioteca é um local de descobertas no qual se pode buscar e encontrar respostas, pesquisar para trabalhos ou simplesmente passar o tempo livre num ambiente acolhedor $\mathrm{e}$ descontraído".

Crippa (2015), considerando as transformações sociais e as novas necessidades dos indivíduos em face do papel social da biblioteca, discute a biblioteca como "laboratórios de cidadania", devendo esses locais oferecerem atividades diversificadas em conformidade com os desejos da comunidade. A concepção dessa autora no que se refere ao papel recreativo e cultural da biblioteca torna essa instituição um seguimento, uma extensão, um espaço que representa a sociedade; logo, as bibliotecas caracterizam-se como espaços abertos, sistêmicos e permanentes de apropriação do espaço coletivo e de ações compartilhadas.

De acordo com as cinco realidades investigadas neste estudo, percebeu-se, conforme relato dos bibliotecários, que as bibliotecas ainda estão presas à função informacional/educativa. Mesmo havendo práticas voltadas para fomentar ações de cunho recreativo e cultural, os usuários ainda recorrem às unidades, de modo geral, para estudar e consultarem materiais bibliográficos.

Embora não seja atividade fim das unidades, constatou-se na observação, que as unidades realizam outras atividades (culturais/recreativa) que extravasem a função puramente informacional. Em três bibliotecas a prática da função social é uma realidade, sendo oferecidos diversos serviços e atividades, tais como: dramatizações, cinema, hora do conto, espaço para reuniões da comunidade, brinquedotecas e salas para exposições e realização de oficinas. Em duas bibliotecas, percebeu-se o interesse e o conhecimento do profissional sobre essas questões, no entanto, as referidas unidades ainda não oferecem esses tipos de atividades/serviços, restringindo-se, tão somente, à oferta de material informacional. 


\section{A BIBLIOTECA FÍSICA NO FUTURO: DE AMBIENTES INFORMACIONAIS A ESPAÇOS DE CONVIVÊNCIA}

O surgimento das coleções digitais e a disponibilização dos objetos informacionais no ciberespaço, facilitando a forma de armazenamento, tratamento, gestão e oferta de serviços e produtos biblioteconômicos são fatores que interferem na redefinição das bibliotecas físicas.

É nesse contexto que se torna relevante reforçar as atividades sociais, voltadas para a cultura e o lazer, haja vista garantir a permanência da biblioteca, em virtude dessas novas potencialidades que são a elas atribuídas. Alguns trabalhos existentes na literatura já evidenciam um futuro em que a função social e a redefinição da biblioteca como espaço de encontros estejam fortemente instituídas.

Ribas e Ziviani (2007, p. 5) proclamam a participação da biblioteca no fomento a uma sociedade mais inclusiva, em que direitos humanos sejam mais respeitados, e os profissionais atuantes nessas instituições serão conduzidos pela trindade: educação a distância, redes sociais e ação cultural. Assim, a biblioteca funcionará como um ambiente de encontro para troça de informações, lazer, cultura, discussão e propostas de resolução dos problemas sociais.

Não resta dúvida de que, se as novas tecnologias trazem novas configurações quanto aos fazeres técnicos realizados com os documentos, a biblioteca continuará produzindo conhecimento, não mais por meio do armazenamento e disponibilização das coleções documentárias, mas pelo contato e interação física entre as pessoas. Ademais, "A biblioteca, o arquivo, o centro cultural, o museu, todos os centros de informação de maneira geral se convergem num espaço aberto, de diálogo e troca de informações, deixando de ser apenas um local de consulta para se tornar um espaço de convivência [...]”. As autoras presumem que ao criar condições para que os indivíduos reflitam criticamente sobre a produção cultural da sociedade, o profissional que gerencia a biblioteca contribuirá para a formação de uma sociedade mais inclusiva (RIBAS; ZIVIANI, 2007, p. 55, grifo nosso).

Percebe-se a expansão da missão e do comprometimento social do bibliotecário e da biblioteca. Por conseguinte, a relação e importância das bibliotecas com a sociedade se fazem melhores delineadas quando "[...] passamos a apreendê-las como espaços vivenciais e de enraizamento, cujas ações práticas, aliadas à sua força simbólica, refletem as diferentes pulsões da vida social [...]" (SILVEIRA, 2014, p. 147, grifo nosso).

A respeito do posicionamento das bibliotecas físicas no que se refere à migração das coleções impressas para o ambiente digital, Serra (2013) acredita que o ambiente da biblioteca física, a fim de permanecer em utilização, assim como o bibliotecário, deverão ser repensados. A autora propõe que a oferta dos serviços e produtos biblioteconômicos seja realizada de forma variada, em múltiplas tecnologias e, que esses espaços de informação caracterizem-se como ambientes atrativos e acolhedores ao usuário, permitindo interação alinhada com liberdade, não sendo apenas um espaço de troca e aprendizado, mas uma opção de lazer, repleto de oportunidades, de descobertas e de conhecimento. 
A redefinição da biblioteca física no futuro somente ocorrerá à medida que os gestores das bibliotecas e os mantenedores dessas unidades refletirem acerca das necessidades dos usuários. É preciso repensar a aplicação exagerada de normas, desmistificar trabalhos engessados, fomentar atendimento receptivo e acolhedor, visando atrair o público para a utilização de um espaço de socialização e convivência (SANTA ANNA; MAIA, 2015). Os referidos autores discorrem que é a partir das práticas cordiais de acolhimento e oferta de serviços variados e úteis, busca-se pela satisfação do usuário, o que poderá despertar o crescimento dos índices de frequência e a valorização/reconhecimento da biblioteca como instituição necessária à sociedade.

Com efeito, não resta dúvida de que, a transfiguração da biblioteca física para ambientes de convivência, certamente, é a medida mais estratégia para tornar essas instituições presentes e atuantes na sociedade do futuro. Ao refletir acerca dessas transformações e redefinir as práticas bibliotecárias, ao bibliotecário permite-se a concretização de um atendimento dinâmico a todos os tipos de público, sejam eles presenciais quanto virtuais. Quanto às práticas no ambiente físico, a biblioteca deve ser redefinida como um espaço de troca, de aquisição de conhecimentos, que favoreçam a interação e a permanência, reafirmando a biblioteca um local de pesquisa e estudo, mas agregando a condição de espaço de lazer, diversão e atualização.

Essa ocorrência amplia as funções social, recreativa e cultural que há muito tempo foram inseridas nos fazeres bibliotecários, embora não tenham sido praticadas com efetividade e nem valorizadas e reconhecidas pela classe profissional, pelas instituições mantenedoras, pelo poder público, enfim, por toda a sociedade. A redefinição das bibliotecas como ambientes de convívio e troca de conhecimentos entre os indivíduos, adentra essas unidades de informação no contexto social, condicionando-as a serem instrumentos de desenvolvimento pessoal e social, garantindo melhorias na vida dos cidadãos, das famílias e dos grupos sociais.

Analisando essa discussão sobre o futuro da biblioteca física, confirmou-se o que a literatura vem discorrendo, a respeito da transfiguração da biblioteca em espaços de encontro na sociedade. Por meio da entrevista, os bibliotecários foram investigados se acreditavam no papel social das bibliotecas. Por unanimidade, todos responderam que acreditam nesse papel atribuído às bibliotecas. Semelhantemente, quando indagados se crêem que as bibliotecas um dia poderão tornar-se locais de convivência, também todos os cinco responderam que acreditam nessa possibilidade. Quanto às atividades sociais, seja de recreação ou cultural, apenas três bibliotecas realizam essas atividades. Contudo, é importante enfatizar que, mesmo naquelas que não oferecem essas atividades, o conhecimento e atuação do profissional sobre esse potencial da biblioteca ficou evidenciado.

Assim, percebe-se que os profissionais que atuam nas bibliotecas investigadas possuem conhecimento das novas potencialidades das unidades, sobretudo quanto ao papel social que elas podem desempenhar. Com base nas respostas de dois bibliotecários, de que a biblioteca não oferece atividades sociais, depreende-se que se trata de motivos não 
relacionados com o posicionamento dos profissionais, mas motivos de ordens mais genéricas, envolvendo outras instâncias e contextos.

Em linhas gerais, os bibliotecários reconhecem as funcionalidades da biblioteca que extrapolam as tradicionais funções informacionais (acervo). Ao serem perguntados: "Se, porventura, os acervos impressos forem transferidos para ambiente virtual, você considera que a biblioteca presencial será extinta?". Todos consideram que a biblioteca presencial permanecerá com espaços destinados à visitação de usuários, haja vista, realizar estudos, pedir auxílios aos bibliotecários, assim como participar de atividades sociais, dentre elas: encontros, palestras, teatros, debates, enfim, um local de convívio social.

\section{6 À GUISA DE CONCLUSõES}

De acordo com as análises realizadas na literatura e com bibliotecários, considerando as unidades e contextos em que atuam, foi possível perceber, em linhas gerais, que, na contemporaneidade, a biblioteca extrapolou sua função meramente informacional, exercendo também funções sociais. Com essa constatação, presume-se que no futuro, a biblioteca ampliará suas funções deixando de ser um ambiente meramente informacional para transformar-se em espaços de convivência.

Embora se encontram na literatura, trabalhos que reflitam acerca das funções sociais, culturais e recreativas como novos potenciais atribuídos às bibliotecas do futuro, percebe-se que a quantidade de publicações ainda é escassa, diante da importância e necessidade de se discutir a temática, sobretudo diante dos desafios oriundos com a revolução tecnológica e as diversificadas exigências dos usuários da informação.

As realidades analisadas neste estudo demonstram o quanto os bibliotecários possuem conhecimento a respeito das novas funções da biblioteca e o engajamento dessa instituição no contexto social. Embora as atividades bibliotecárias, na grande maioria, ainda contemplem a função informacional/educacional, notou-se a percepção do bibliotecário quanto à modificação da biblioteca no futuro, a qual passará a atuar como espaços de relacionamento. Presume-se, que a morosidade na realização de projetos voltados para as práticas sociais, bem como a escassez na realização de atividades de aspecto social deve-se a problemas de valorização/conhecimento por parte dos órgãos mantenedores, das autoridades governamentais e da própria comunidade.

Por fim, este estudo não se dá por encerrado; ao contrário, abre espaços para outras

pesquisas. É preciso ampliar a discussão, demonstrando o potencial da biblioteca como instituição democrática, social, a serviço das comunidades e viabilizadora de desenvolvimento pessoal, social, político e econômico. 


\section{REFERÊNCIAS}

BAPTISTA, Sofia Galvão. Profissional da informação, autônomo ou empresário, novas perspectivas de mercado de trabalho. Perspectiva em Ciência da Informação, Belo Horizonte, v. 5, n. 1, p. 91 - 98, jan./jun. 2000. Disponível em: <http://portaldeperiodicos.eci. ufmg.br/index.php/pci/article/view/550/467>. Acesso em: 17 ago. 2015.

BENÍCIO, Christine Dantas; SILVA, Alzira Karla Araújo da. Do livro impresso ao e-book: o paradigma do suporte na Biblioteca Eletrônica. Biblionline, v. 1, n. 2, 2005. Disponível em: <file:///H:/Documents\%20and\%20Settings/Convidado/Meus\%20documentos/Downloads/58 0-629-1-PB.pdf>. Acesso em: 17 ago. 2015.

BERNARDINO, Maria Cleide Rodrigues; SUAIDEN, Emir José. O papel social da biblioteca pública na interação entre informação e conhecimento no contexto da ciência da informação. Perspectivas em Ciência da Informação, Belo Horizonte, v. 16, n. 4, p. 29-41, out./dez. 2011. Disponível em: <http://www.scielo.br/pdf/pci/v16n4/v16n4a04.pdf>. Acesso em: 17 ago. 2015.

BEZERRA, Fabiana de Oliveira; SILVA, Alzira Karla Araújo da. A biblioteca particular e sua função social: um espaço de (in)formação de leitores. Biblionline, João Pessoa, v. 4, n. 1/2, 2008. Disponível em: <file:///H:/Documents\%20and\%20Settings /Convidado /Desktop/3 140-4958-1-PB.pdf>. Acesso em: 17 ago. 2015.

CRIPPA, Giulia. Pensando o espaço público do presente: a biblioteca pública em sua função social. DataGramaZero, Rio de Janeiro, v. 16, n. 2, abr. 2015. Disponível em: < http://www.dgz.org.br/abr15/Art_04.htm>. Acesso em: 18 ago. 2015.

CUNHA, Murilo Bastos da. A biblioteca universitária na encruzilhada. DataGramaZero, Rio de Janeiro, v. 11, n. 6, dez. 2010. Disponível em: <http://www.datagramazero.org. br/dez10/Art_07.htm>. Acesso em: 20 fev. 2013.

DIAS, Eduardo Wense. Organização da informação no contexto das bibliotecas tradicionais e digitais. In: NAVES, Madalena Martins Lopes; KURAMOTO, Hélio (Org.). Organização da informação: princípios e tendências. Brasília: Briquet de Lemos, 2007.

FLUSSER, Victor. O bibliotecário animador: considerações sobre sua formação. Revista da Escola de Biblioteconomia da UFMG, Belo Horizonte, v. 11, n. 2, p. 230-236, 1982. Disponível em: <http://www.brapci.ufpr.br/documento.php?dd0=0000002902\&dd1=1b7f1>. Acesso em: 29 abr. 2014.

GONÇAlVES, Maria da Graça Simão. A Biblioteca Pública do Paraná como instrumento de ação cultural: atividades e mediação da informação. Londrina: UEL, 2011. Disponível em: <http://www.bibliotecadigital.uel.br/document/?code=vtls000173811>. Acesso em: 18 ago. 2015.

LANCASTER, F. W. Future librarianship: preparing for an unconvencional career. Wilson Library Bulletin, v. 57, p. 747-53, maio, 1983. 
LANKES, David. Expect More: demanding better libraries for today's complex world. [S.L.]: [sine nomine], 2012.

LÉVY, Pierre. Cibercultura. 2. ed. São Paulo: Ed. 34, 2000.

MADUREIRA, Helania Oliveira; VILARINHO, Lúcia Regina Goulart. A formação do bibliotecário para atuar em bibliotecas digitais: uma questão a aprofundar. Perspectivas em Ciência da Informação, Belo Horizonte, v. 15, n. 3, p. 87-106. 2010. Disponível em: < http://www.scielo.br/pdf/pci/v15n3/06.pdf>. Acesso em: 17 ago. 2015.

MILANESI, Luís. Biblioteca. Cotia: Ateliê Editorial, 2002.

OLIVEIRA, Magali Araújo Damasceno de; ALVES, Márcia Valéria; MAIA, Maria Aniolly Queiroz. A função social do profissional da informação numa biblioteca inclusiva. Disponível em: < portal.febab.org.br/anais/article/download/1600/1601>. Acesso em: 05 jul. 2015.

RIBAS, Cláudia S. da Cunha; ZIVIANI, Paula. O profissional da informação: rumos e desafios para uma sociedade inclusiva. Informação e Sociedade: Estudos, João Pessoa, v. 17, n. 3, p. 47-57, set./dez. 2007. Disponível em: < http://www.ies.ufpb.br/ojs/index.php/ies/article/view/638/1614>. Acesso em: 08 jul. 2015.

ROSA, Anelise Jesus Silva da. A prática de ação cultural em bibliotecas. Revista ACB: Biblioteconomia em Santa Catarina, Florianópolis, v. 14, n. 2, 372-381, jul./dez., 2009. Disponível em: <www.brapci.ufpr.br/download.php?dd0=10849>. Acesso em: 18 ago. 2015.

SANTA ANNA, Jorge. O bibliotecário em face das transformações sociais: de guardião a um profissional desinstitucionalizado. Revista ACB: Biblioteconomia em Santa Catarina, Florianópolis, v. 20, n. 1, p. 138-157, jan./abr., 2015. Disponível em: $<$ http://revista.acbsc.org.br/racb/article/view/985/pdf_118>. Acesso em: 17 ago. 2015.

SANTA ANNA, Jorge. O futuro do profissional bibliotecário: desmistificando previsões exageradas. Biblionline, João Pessoa, v. 10, n. 2, p. 1-16, 2014. Disponível em: $<$ http://periodicos.ufpb.br/ojs2/index.php/biblio/article/view/17824/12474>. Acesso em: 17 ago. 2015.

SANTA ANNA, Jorge. GREGÓRIO, Elaine; GERLIN, Meri Nádia Marques. Atuação bibliotecária além da biblioteca: o espaço de leitura do Hospital Universitário Cassiano de Moraes (HUCAM). Revista ACB: Biblioteconomia em Santa Catarina, Florianópolis, v. 19, n. 1, p. 77-88, jan./jun., 2014. Disponível em: <file://H:/Documents\%20and\%20Settings/Convidado/ Meus\%20d ocume ntos/Downloads/953-4415-1-PB\%20(5).pdf>. Acesso em: 17 ago. 2015.

SANTA ANNA, Jorge. MAIA, Maria de Lourdes Franklin. Manifestações simbólicas de punição/proibição em bibliotecas: espaços de acolhimento ou coerção? Revista ACB: Biblioteconomia em Santa Catarina, Florianópolis, v. 20, n. 2, p. 272-285, maio./ago., 2015. Disponível em: < http://revista.acbsc.org.br/racb/article/view/988/pdf> Acesso em: 18 ago. 2015. 
SANTA ANNA, Jorge. PEREIRA, Gleice; CAMPOS, Suelen de Oliveira. Sociedade da informação x biblioteconomia: em busca do moderno profissional da informação (MIP). Revista Brasileira de Biblioteconomia e Documentação. São Paulo, v. 10, n. 1, p. 68-85, jan./jun. 2014. Disponível em: < http://rbbd.febab.org.br/rbbd/article/viewFile/293/293>. Acesso em: 17 ago. 2015.

SANTA ANNA, Jorge. ZANETTI, Eni Maria de Souza Pinto; NASCIMENTO, Lucileide Andrade de Lima do. Bibliotecas prisionais e a construção da cidadania: um estudo teórico das práticas bibliotecárias em favor da inclusão social. Revista ACB: Biblioteconomia em Santa Catarina, Florianópolis, v. 20, n. 1, p. 67-85, jan./abr., 2015. Disponível em: < file://H:/Documents\%20and\%20Settings/Convidado/Desktop/984-4754-1-PB.pdf>. Acesso em: 17 ago. 2015.

SANTOS, Josiel Machado. O processo evolutivo das bibliotecas da antiguidade ao renascimento. Revista Brasileira de Biblioteconomia e Documentação. São Paulo, v. 8, n. 2, p. 175-189, jul./dez. 2012. Disponível em: <http://rbbd.febab.org.br/rbbd/article/view/237/235>. Acesso em: 17 ago. 2015.

SERRA, Liliana Giusti. Bibliotecas do futuro e o foco no usuário. CRB-8 Digital, São Paulo, v. 6, n. 1, p. 11-19, ago. 2013. Disponível em: <http://www.crb8.org.br/ UserFiles/File/Artigo_Bibliotecas\%20do $\% 20$ futuro $\% 20 \mathrm{e} \% 20 \mathrm{o} \% 20 \mathrm{foco} \% 20$ no $\% 20 \mathrm{usu} \% \mathrm{C} 3$ \%A1rio.pdf>. Acesso em: 18 ago. 2015.

SILVEIRA, Fabrício José Nascimento da. Biblioteca pública e identidade: percepções intersubjetivas enraizadas em torno da Luiz de Bessa. Perspectivas em Ciência da Informação, Belo Horizonte, v. 19, número especial, p.128-150, out./dez. 2014. Disponível em: < http://portaldeperiodicos.eci.ufmg.br/index.php/pci/article/viewFile/2283/1474>. Acesso em: 17 ago. 2015.

SILVEIRA, Fabrício José Nascimento da. O bibliotecário como agente histórico: do "humanista" ao "Moderno Profissional da Informação". Informação e Sociedade: Estudos, João Pessoa, v. 18, n. 3, p. 83-94, set./dez. 2008. Disponível em: < http://www.ies.ufpb.br/ojs/index.php/ies/article/view/1873/2275>. Acesso em: 17 ago. 2015.

SILVEIRA, Fabrício José Nascimento da. REIS, Alcenir Soares dos. Biblioteca pública como lugar de práticas culturais: uma discussão sócio-histórica. Informação e Sociedade: Estudos, João Pessoa, v. 21, n. 1, p. 37-54, jan./abr. 2011. Disponível em: $<$ http://www.ies.ufpb.br/ojs/index.php/ies/article/view/3740/5597>. Acesso em: 17 ago. 2015 .
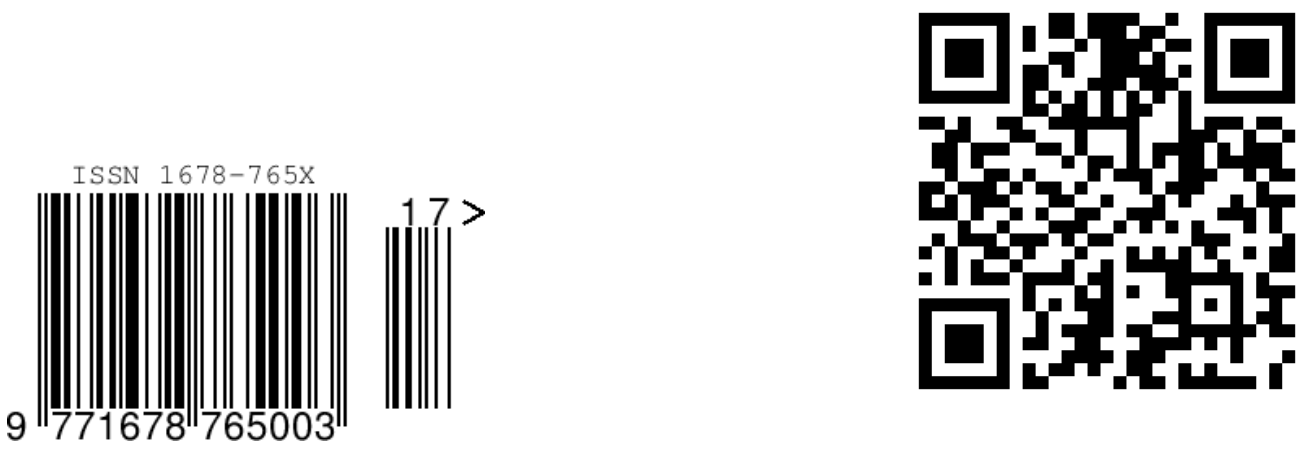